\title{
Bulk segregant analysis (BSA) for improving cold stress resistance in maize using SSR markers
}

\author{
M.Q.U. Farooqi*, K.J. Sa*, T.K. Hong and J.K. Lee \\ Department of Applied Plant Sciences, \\ College of Agriculture and Life Sciences, \\ Kangwon National University, Chuncheon, Korea \\ *These authors contributed equally to this study. \\ Corresponding author: J.K. Lee \\ E-mail: jukyonglee@kangwon.ac.kr \\ Genet. Mol. Res. 15 (4): gmr15049326 \\ Received September 21, 2016 \\ Accepted December 1, 2016 \\ Published December 19, 2016 \\ DOI http://dx.doi.org/10.4238/gmr15049326
}

Copyright (C) 2016 The Authors. This is an open-access article distributed under the terms of the Creative Commons Attribution ShareAlike (CC BY-SA) 4.0 License.

\begin{abstract}
In this study, eight inbred maize lines with high or low tolerance to cold temperature were investigated using bulk segregant analysis (BSA). Genetic diversity and genetic relationships were investigated using 100 simple sequence repeat (SSR) markers linked to cold tolerance in maize. A total of 319 alleles were identified. Among these, 128 were high coldtolerant-specific alleles and 61 were poorly coldtolerant-specific alleles, while the remaining 130 were shared between the two types. The number of alleles per locus ranged from 2 to 5 , with an average of 3.19. The major allele frequency varied from 0.39 to 0.53 with an average of 0.47 . The average gene diversity and polymorphic information content among all lines were 0.63 and 0.58 , respectively. A dendrogram analysis identified three main clusters and most of the high tolerant inbred lines were clearly distinguished from
\end{abstract}

Genetics and Molecular Research 15 (4): gmr15049326 
the poorly tolerant inbred lines. In addition to the BSA, a total of 84 SSR markers were identified as high cold tolerance-specific alleles and 52 SSRs were detected as poorly cold tolerance-specific alleles. Of these, bnlg1273, umc1124, dupssr21, mmc0251, mmc0181, and phi041 have great potential for being molecular markers for cold tolerance in maize. Our results were in agreement with results previously reported for SSR markers linked with cold tolerance in maize. The identification and characterization of high and poorly cold tolerant maize lines based on SSR markers will be useful for future maize breeding studies.

Key words: Maize; Zea mays L.; Bulk segregant analysis; Cold tolerance; SSR marker; Genetic diversity

\section{INTRODUCTION}

Improving the cold stress resistance of crop plants is a major objective for breeders in tropical, sub-tropical, and warm temperate parts of the world. Maize is highly sensitive to low temperature, due to its tropical origin. Abiotic stresses have adverse effects on plant physiology, growth, and biochemical processes (Farooqi et al., 2012). Maize has expanded to cooler regions of the world in the last 50 years, due to improved cold tolerance of modern maize varieties. Cold temperatures are an important constraint for global maize production, as it is not favorable for early seedling growth in crop plants (Guan et al., 2009). Currently, maize is cultivated at a wide range of altitudes. High yielding germplasms are sensitive to low temperatures and the varieties that are associated with cold tolerance tend to produce lower yields (Revilla et al., 2005). To maintain higher production, many adaptations have been made. In the northern and southern hemispheres, maize cultivation is limited because cooler regions are not easily adoptable for germination. Germination energy, germination rate, root length, and shoot length are all affected in plants due to stress conditions. However, it is hard to measure cold tolerance in the field due to the fluctuation of environmental conditions. Furthermore, seed storage under varying climate conditions is not trivial. Hence, it is essential to identify maize lines that are highly resistant to cold temperatures (Mirosavljević et al., 2013).

The productivity of a maize plant can be altered due to cold stress. Low temperature disturbs the mean germination time and is directly correlated with shoot length and dry weight of the plant. Low temperature also affects the photosynthetic rate and may cause oxidative stress and cell damage (Riva-Roveda and Périlleux, 2015). Furthermore, if the temperature falls rapidly, water present in intracellular spaces is converted into crystals that can damage the cell wall, cell membrane, and other organelles (Mazur, 2004). To resist against insects, it is essential for crop plants to grow vigorously. Moreover, cold temperature also affects plant morphology and biomass production (Strigens et al., 2013). In the early stages of maize growth, biomass accumulation in crop plants is reduced due to cold sensitivity (Frei, 2000). It is important to identify cold tolerant maize strains in response to fluctuating environmental conditions.

Gene expression can be changed in response to low temperatures. It is essential to know how cold tolerant a plant is in order to identify the gene that is responsible for cold stress. Modification in the pattern of gene expression allows plants to adapt to stressful conditions. Genes related to stress resistance can be elucidated through germination testing. Adaptation is important for the survival of plants and maintenance of crop yield (Sanghera

Genetics and Molecular Research 15 (4): gmr15049326 
et al., 2011). Early seasonal adaptability can be assessed by observing traits linked to cold tolerance (Hoffman et al., 2015). Under certain environmental conditions, there is great variability among maize inbred lines because both the physiological responses of the plants and their efficient breeding slow down at low temperatures. Revilla et al. (2000) revealed that cold tolerance is an important trait related to the vegetative period of the maize plant.

For the development of new maize varieties, it is important to have knowledge about genetic diversity and the relationship among breeding plants. The assessment of genetic diversity has historically been accomplished by using morphological data such as pedigrees, amount of heterosis by hybrid expression, and endosperm type of inbred lines. Cold tolerance involves various additive, dominant, and maternal effects and is, therefore, a complex trait with polygenic inheritance. Maize breeding for cold tolerance attains less success in yield production. The main hindrance to produce cold tolerant varieties is low heritability and fitness (Mahajan et al., 1993; Revilla et al., 2000; 2005). Seed origin plays an important role in the interaction of the genotype with the environment, due to the cold tolerance trait showing low heritability (Revilla et al., 2005).

Physiologists have had to rely upon phenotypic correlation analyses using genetic stocks differing in expression of a particular trait, to test the association between various traits and yield. However, the development of molecular marker technologies has changed this trend. Bulk segregant analysis (BSA) is a valuable tool that has been used to identify molecular markers for numerous plant types. Two variants of the BSA technique are available, depending on whether the plants are derived from a cross between two parental lines or from a population of plants with diverse genetic backgrounds. The difference can be found among genotypes, which, unlike the morphological markers, are not influenced by environmental factors (Legesse et al., 2007). Microsatellites, or simple sequence repeat (SSR) genetic markers, are di-, tri-, or tetra-nucleotide motifs with short stretches of tandem repeats. SSR markers are abundant and highly variable in the plant genome (Matsuoka et al., 2002). SSRs are multi-allelic, highly polymorphic, and co-dominant in nature, which makes them one of the most useful genetic markers for breeders in molecular analysis of crops (Gupta and Varshney, 2000). SSRs have proven to be a valuable tool for genomic mapping, population and conservation genetics studies, property right protection, marker-assisted selection, and diversity measurements in maize (Warburton et al., 2002; Pinto et al., 2003).

The objective of this study was to identify promising cold tolerance maize cultivars and to characterize the genetic relationship between high and poorly cold tolerance varieties. Thus, our BSA results may be used to help identify traits important in determining cold stress resistance of maize strains. In addition, markers identified by BSA can be used to help incorporate such traits into a breeding program to improve cold stress resistance in maize.

\section{MATERIAL AND METHODS}

\section{Plant material}

A screen from a cold germination test resulted in a total of eight maize lines that were used in this study. Among these, five (CO439, CO438, CO450, CO435, and CO445) had high tolerance against cold temperatures and were referred to as cold tolerant lines, whereas three (CO437, CO436, and CO440) had poorly tolerance and were referred to as cold susceptible lines (Table 1).

Genetics and Molecular Research 15 (4): gmr15049326 
Table 1. Derivation of the eight high and low cold tolerant maize inbred lines used in this study.

\begin{tabular}{l|l|l|l|l}
\hline Code No. & Inbred name & Derivation/Source & Heterotic group & Type \\
\hline 1 & CO439 & Nebraska BSSS & BSSS & High tolerant/inbred line \\
\hline 2 & CO438 & CB3 x CL29 & P3994 & High tolerant/inbred line \\
\hline 3 & CO450 & Eyespot Resistant Synthetic (99ESR) & BSSS/Mix & High tolerant/inbred line \\
\hline 4 & CO435 & A632 x A634 & BSSS & High tolerant/inbred line \\
\hline 5 & CO445 & CO386 x W64AHt & Lancaster & High tolerant/inbred line \\
\hline 7 & CO437 & European Synthetic & European Flint & Poorly tolerant/inbred line \\
\hline 8 & CO436 & CO275 x CO300 & P3994 & Poorly tolerant/inbred line \\
\hline
\end{tabular}

\section{DNA isolation}

Leaf tissue from each inbred line was harvested from three- to four-week-old seedlings. Genomic DNA was extracted using the method of Dellaporta et al. (1983) with minor modifications. Briefly, about 50-70 mg leaf tissue from each inbred line was placed in a 2-mL screw-cap tube containing $800 \mu \mathrm{L} \mathrm{5 \%} \mathrm{CTAB} \mathrm{extraction} \mathrm{buffer.} \mathrm{The} \mathrm{leaf} \mathrm{tissues}$ were homogenized into fine pastes using a FastPrep ${ }^{\circledR}$ FP120 Instrument (QBiogene, Carlsbad, CA, USA) and then incubated at $65^{\circ} \mathrm{C}$ for $60 \mathrm{~min}$. The samples were extracted once with chloroform iso-amyl alcohol (24:1) and precipitated twice with 70 and $95 \%$ ethanol. The pellets were air dried and re-suspended in $100 \mu \mathrm{L} \mathrm{TE}(10 \mathrm{mM}$ Tris-HCl, $\mathrm{pH} 8.0$, and $0.2 \mathrm{mM}$ EDTA). The DNA concentration was estimated by comparison to a serial dilution of lambda DNA standard on a $1 \%$ agarose gel and adjusted to approximately $10 \mathrm{ng} / \mu \mathrm{L}$.

\section{BSA, SSR primers, and polymerase chain reaction (PCR) amplification}

The selected markers were those that had polymorphisms in the form of a clearly visible difference in band patterns between the high and poorly tolerant inbred lines. High and poorly cold tolerant inbred lines were screened for polymorphisms using SSR-specific primers. A total of 100 SSR primers were selected from Maize GDB (http://www.maizegdb.org/), related to the cold tolerance trait (Enoki et al., 2002; Jompuk et al., 2005; Reid et al., 2011).

SSR amplifications were performed in a total volume of $30 \mu \mathrm{L}$ and consisted of 20 ng genomic DNA, 1X PCR buffer, $0.3 \mu \mathrm{M}$ forward and reverse primers, $0.2 \mathrm{mM}$ dNTPs, and $1 \mathrm{U} / \mu \mathrm{L}$ Taq Polymerase (BIOTOOLS B\&M Labs, S.A., Madrid, Spain). The PCR cycling conditions were as follows: initial denaturation at $94^{\circ} \mathrm{C}$ for $5 \mathrm{~min}$, followed by two denaturation cycles at $94^{\circ} \mathrm{C}$ for $1 \mathrm{~min}$, annealing at $65^{\circ} \mathrm{C}$ for $1 \mathrm{~min}$, and extension at $72^{\circ} \mathrm{C}$ for $2 \mathrm{~min}$. The annealing temperature was decreased by $1{ }^{\circ} \mathrm{C}$ in every second cycle until it reached to $55^{\circ} \mathrm{C}$. The last cycle was repeated 20 times. When the cycles were complete, the extension cycle was extended for $10 \mathrm{~min}$ at $72^{\circ} \mathrm{C}$.

\section{SSR data analysis}

Gel photographs were scored manually. For each genotype, the bands were binary coded as 1 or 0 for their presence or absence, respectively. A genetic dendrogram was constructed on the basis of Sxy $=2 \mathrm{Nxy} /(\mathrm{Nx}+\mathrm{Ny})$, where Nxy refers to the number of bands in common between plant $\mathrm{x}$ and $\mathrm{y}$. $\mathrm{Nx}$ and $\mathrm{Ny}$ denote the total number of bands in each plant $\mathrm{x}$ and $\mathrm{y}$, respectively (Nei and $\mathrm{Li}, 1979)$. The calculations were performed using the arithmetic 
average option in NTSYS-pc per Rohlf (1992). Using the genetic analysis package Power Marker v. 3.25 by Liu and Muse (2005), variability at each locus [number of alleles $\left(N_{\mathrm{A}}\right)$, major allele frequency (MAF), gene diversity (GD), and polymorphic information content (PIC)] was measured. The PIC value can be used to evaluate diversity using the following formula:

$$
P I C=1-\sum_{u=1}^{k} p_{l u}^{2}-\sum_{u=1}^{k-1} \sum_{v=u+1}^{k} 2 p_{l u}^{2} p_{l v}^{2}
$$

where $\mathrm{p}_{\mathrm{lu}}$ and $\mathrm{p}_{\mathrm{lv}}$ are the frequencies of alleles $\mathrm{u}$ and $\mathrm{v}$, respectively.

\section{RESULTS}

\section{Genetic diversity among maize inbred lines}

The evaluation of genetic diversity was based on the MAF, GD, and PIC values calculated from allele scoring data of SSR loci linked with cold tolerance. The MAF of all lines was found to average 0.47 . The average $N_{\mathrm{A}}$ per locus was 3.19, ranging from 2 to 5 alleles per locus. The average GD value was 0.63 , varying from 0.59 to 0.73 , whereas the average PIC value was 0.58 (Table 2 and Table S1). In high tolerant inbred lines, the $N_{\mathrm{A}}$, GD, and PIC values were $1.53,0.59$, and 0.52 , respectively. In comparison, for poorly tolerant inbred lines, the $N_{\mathrm{A}}, \mathrm{GD}$, and PIC were $1.17,0.53$, and 0.44 , respectively. The mean MAF value was 0.44 and 0.35 in the high and poorly tolerant inbred lines, respectively. A comparison of the GD among high and poorly tolerant inbred lines showed that, with the exception of MAF, all values were higher in high cold tolerant inbred lines (Table 3 and Table S2).

Table 2. Mean number of alleles and genetic diversity index for SSR loci linked to cold tolerance among high tolerant maize inbred lines.

\begin{tabular}{l|c|c|c|c}
\hline Chromosome & Major allele frequency & Allele No. & Gene diversity & PIC* \\
\hline 1 & 0.53 & 66 & 0.59 & 0.53 \\
\hline 2 & 0.43 & 38 & 0.67 & 0.62 \\
\hline 3 & 0.52 & 31 & 0.60 & 0.55 \\
\hline 4 & 0.48 & 30 & 0.60 & 0.58 \\
\hline 5 & 0.52 & 29 & 0.58 & 0.51 \\
\hline 6 & 0.51 & 23 & 0.69 & 0.52 \\
\hline 7 & 0.43 & 38 & 0.69 & 0.65 \\
\hline 8 & 0.39 & 19 & 0.70 & 0.65 \\
\hline 9 & 0.42 & 23 & 0.73 & 0.65 \\
\hline 10 & 0.47 & 22 & & 0.58 \\
\hline Total & & 319 & 0.63 & \\
\hline Mean & 0.47 & 3.19 & & \\
\hline
\end{tabular}

*Polymorphic information content.

\section{Identification of specific alleles related to cold tolerance}

In the molecular experimentation for BSA, high and poorly cold tolerant maize inbred lines were assessed using 100 SSR primer sets. The amplified SSR locus fragments ranged from 50 to $600 \mathrm{bp}$ but most bands were located in the 50-300 bp size range. The alleles

Genetics and Molecular Research 15 (4): gmr15049326 
that were observed only in high tolerant lines were designated as high cold tolerance-specific alleles, whereas poorly cold tolerance-specific alleles were those that were found exclusively in the poorly tolerant lines. In addition to these, alleles that were observed in both high and poorly tolerant lines were named shared alleles. A total of 319 alleles specific to either high cold tolerance or poorly cold tolerance strains were identified (Figure 1). High cold tolerancespecific alleles were detected in 84 SSR markers, whereas poorly cold tolerance-specific alleles were found in 52 SSR markers (Table 4).

Table 3. Mean number of alleles and genetic diversity index for SSR loci linked to cold tolerance between high and poorly tolerant maize inbred lines.

\begin{tabular}{l|c|c|c|c|c|c|c|c}
\hline \multirow{2}{*}{ Chr } & \multicolumn{9}{|c|}{ High tolerant } & \multicolumn{4}{c}{ Poorly tolerant } \\
\cline { 2 - 9 } & MAF* & Allele No. & GD** & PIC*** & MAF* & Allele No. & GD** & PIC*** \\
\hline 1 & 0.44 & 28 & 0.53 & 0.47 & 0.40 & 15 & 0.51 & 0.42 \\
\hline 2 & 0.45 & 17 & 0.61 & 0.53 & 0.39 & 8 & 0.47 & 0.38 \\
\hline 3 & 0.45 & 12 & 0.55 & 0.48 & 0.33 & 9 & 0.53 & 0.44 \\
\hline 4 & 0.47 & 13 & 0.55 & 0.49 & 0.33 & 6 & 0.48 & 0.39 \\
\hline 5 & 0.44 & 11 & 0.54 & 0.48 & 0.31 & 4 & 0.50 & 0.41 \\
\hline 6 & 0.55 & 10 & 0.63 & 0.55 & 0.42 & 3 & 0.59 & 0.51 \\
\hline 7 & 0.37 & 14 & 0.60 & 0.54 & 0.42 & 7 & 0.58 & 0.49 \\
\hline 8 & 0.40 & 6 & 0.70 & 0.64 & 0.33 & 3 & 0.52 & 0.43 \\
\hline 9 & 0.43 & 10 & 0.66 & 0.60 & 0.33 & 4 & 0.61 & 0.53 \\
\hline 10 & 0.44 & 7 & 0.72 & 0.68 & 0.23 & 2 & 0.67 & 0.59 \\
\hline Total & & 128 & & & & 61 & & \\
\hline Mean & 0.44 & 1.53 & 0.59 & 0.52 & 0.35 & 1.17 & 0.53 & 0.44 \\
\hline
\end{tabular}

*Major allele frequency. **Genetic diversity. ***Polymorphic information content.

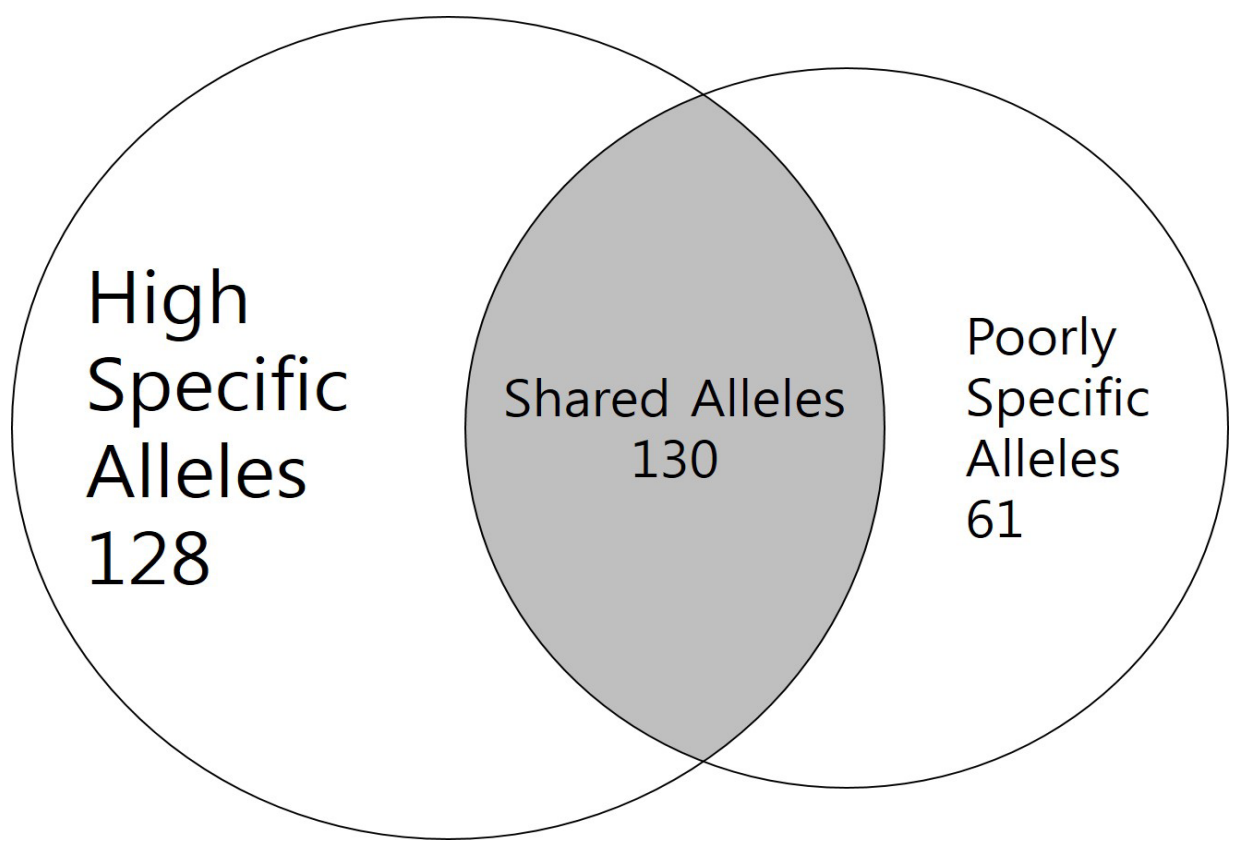

Figure 1. Venn diagram of the number of high, poorly, and shared cold tolerant-specific alleles. 
Table 4. Identification of cold tolerance-specific alleles between high and poorly tolerant linked SSR loci.

\begin{tabular}{|c|c|c|c|c|c|c|c|}
\hline \multicolumn{4}{|c|}{ High tolerant-specific alleles } & \multicolumn{4}{|c|}{ Poorly tolerant-specific alleles } \\
\hline Chr. & SSR & S.A.* & Size (bp) & Chr. & SSR & S.A.* & Size (bp) \\
\hline 1 & phi094 & 1 & 162 & 1 & phi094 & 1 & 166 \\
\hline 1 & umc1797 & 1 & 158 & 1 & phi64 & 1 & 150 \\
\hline 1 & phil20 & 2 & 166,150 & 1 & umc1013 & 1 & 101 \\
\hline 1 & umc1013 & 2 & 144,122 & 1 & umc1278 & 2 & 126,98 \\
\hline 1 & umc1976 & 1 & 172 & 1 & umc1124 & 2 & 139,132 \\
\hline 1 & umc1278 & 1 & 132 & 1 & bnlg1564 & 2 & 147,144 \\
\hline 1 & umc1106 & 1 & 211 & 1 & $\mathrm{mmc} 0041$ & 2 & 160,144 \\
\hline 1 & umc1124 & 3 & $149,144,135$ & 1 & dupsse12 & 1 & 88 \\
\hline 1 & umc1144 & 1 & 138 & 1 & bnlg1007 & 2 & 200,180 \\
\hline 1 & bnlg1564 & 2 & 158,152 & 1 & phi056 & 1 & 126 \\
\hline 1 & $\mathrm{mmc} 0041$ & 2 & 164,162 & 2 & phi083 & 2 & 142,132 \\
\hline 1 & dupssr12 & 1 & 115 & 2 & phi109642 & 1 & 133 \\
\hline 1 & bnlg1007 & 2 & 220,184 & 2 & umc1551 & 1 & 62 \\
\hline 1 & bnlg1273 & 4 & $210,200,184,148$ & 2 & bnlg1017 & 1 & 116 \\
\hline 1 & umc2149 & 1 & 158 & 2 & bnlg1520 & 1 & 170 \\
\hline 1 & umc1128 & 1 & 144 & 2 & $\mathrm{mmc} 0111$ & 1 & 143 \\
\hline 1 & umc1725 & 1 & 178 & 2 & umc1464 & 1 & 166 \\
\hline 1 & phi056 & 1 & 122 & 3 & umc1012 & 1 & 128 \\
\hline 2 & phi083 & 2 & 150,134 & 3 & $\mathrm{mmc} 0251$ & 1 & 108 \\
\hline 2 & phi109642 & 2 & 144,142 & 3 & umc1639 & 1 & 100 \\
\hline 2 & umc1551 & 1 & 70 & 3 & umc1266 & 1 & 67 \\
\hline 2 & bnlg1520 & 1 & 180 & 3 & umc1394 & 1 & 200 \\
\hline 2 & umc1042 & 2 & 119,100 & 3 & bnlg197 & 1 & 122 \\
\hline 2 & phi127 & 2 & 290,280 & 3 & umc1148 & 1 & 180 \\
\hline 2 & $\mathrm{mmc} 0111$ & 2 & 182,160 & 3 & bnlg1182 & 2 & 112,108 \\
\hline 2 & dupssr21 & 3 & $158,157,147$ & 4 & phi072 & 1 & 122 \\
\hline 2 & umc1464 & 1 & 189 & 4 & nc005 & 1 & 166 \\
\hline 2 & umc1845 & 1 & 172 & 4 & umc1086 & 1 & 90 \\
\hline 3 & umc1012 & 1 & 132 & 4 & umc1031 & 1 & 120 \\
\hline 3 & $\mathrm{mmc} 0251$ & 3 & $133,127,125$ & 4 & phi021 & 1 & 96 \\
\hline 3 & umc1639 & 1 & 95 & 4 & umc1720 & 1 & 190 \\
\hline 3 & umc1394 & 2 & 269,260 & 5 & phi087 & 1 & 114 \\
\hline 3 & bnlg197 & 1 & 100 & 5 & bnlg1695 & 1 & 122 \\
\hline 3 & $\mathrm{mmc} 0022$ & 2 & 105,89 & 5 & phi024 & 1 & 162 \\
\hline 3 & bnlg1182 & 2 & 128,118 & 5 & bnlg1237 & 1 & 157 \\
\hline 4 & phi072 & 1 & 120 & 6 & phi123 & 1 & 66 \\
\hline 4 & bnlg1621 & 1 & 130 & 6 & umc1133 & 1 & 122 \\
\hline 4 & $\mathrm{nc} 005$ & 2 & 179,172 & 6 & bnlg249 & 1 & 154 \\
\hline 4 & umc1086 & 1 & 86 & 7 & phil14 & 2 & 156,146 \\
\hline 4 & umc1031 & 2 & 130,108 & 7 & umc1671 & 1 & 146 \\
\hline 4 & phi021 & 1 & 98 & 7 & umc1015 & 1 & 112 \\
\hline 4 & bnlg2291 & 2 & 184,152 & 7 & phil16 & 2 & 110,82 \\
\hline 4 & umc1142 & 1 & 142 & 7 & phi034 & 1 & 98 \\
\hline 4 & umc1720 & 2 & 199,198 & 8 & umc1287 & 1 & 143 \\
\hline \multicolumn{4}{|c|}{ High tolerant-specific alleles } & \multicolumn{4}{|c|}{ Poorly tolerant-specific alleles } \\
\hline Chr. & SSR & S.A.* & Size (bp) & Chr. & SSR & S.A.* & Size (bp) \\
\hline 5 & phi087 & 1 & 178 & 8 & bnlg1823 & 1 & 141 \\
\hline 5 & phi008 & 1 & 178 & 8 & $\mathrm{mmc0181}$ & 1 & 78 \\
\hline 5 & umc1225 & 1 & 182 & 9 & umc1357 & 1 & 160 \\
\hline 5 & bnlg1695 & 2 & 126,109 & 9 & umc1733 & 1 & 152 \\
\hline 5 & bnlg389 & 2 & 117,108 & 9 & phi065 & 1 & 134 \\
\hline 5 & phi024 & 1 & 164 & 9 & umc1957 & 1 & 180 \\
\hline 5 & bnlg1237 & 1 & 162 & 10 & bnlg210 & 1 & 126 \\
\hline 5 & umc2036 & 2 & 162,144 & 10 & phi041 & 1 & 112 \\
\hline 6 & $\mathrm{nc} 013$ & 2 & 186,158 & & & & \\
\hline 6 & umc1653 & 2 & 104,90 & & & & \\
\hline 6 & umc1178 & 1 & 114 & & & & \\
\hline 6 & umc1133 & 2 & 138,126 & & & & \\
\hline 6 & umc 2059 & 1 & 112 & & & & \\
\hline 6 & bnlg249 & 2 & 182,130 & & & & \\
\hline 7 & phil14 & 2 & 166,158 & & & & \\
\hline 7 & umc1671 & 1 & 158 & & & & \\
\hline 7 & umc1359 & 1 & 200 & & & & \\
\hline 7 & umc1125 & 1 & 140 & & & & \\
\hline
\end{tabular}




\begin{tabular}{|c|c|c|c|c|c|c|c|}
\hline \multicolumn{4}{|c|}{ High tolerant-specific alleles } & \multicolumn{4}{|c|}{ Poorly tolerant-specific alleles } \\
\hline Chr. & SSR & S.A.* & Size (bp) & Chr. & SSR & S.A.* & Size (bp) \\
\hline 7 & umc2142 & 2 & 106,102 & & & & \\
\hline 7 & bnlg434 & 2 & 164,156 & & & & \\
\hline 7 & umc1015 & 1 & 94 & & & & \\
\hline 7 & bnlg657 & 2 & 112,105 & & & & \\
\hline 7 & phil16 & 1 & 101 & & & & \\
\hline 7 & umc1066 & 1 & 142 & & & & \\
\hline 8 & phi080 & 1 & 154 & & & & \\
\hline 8 & bnlg1823 & 1 & 192 & & & & \\
\hline 8 & bnlg1863 & 1 & 141 & & & & \\
\hline 8 & mmc0181 & 3 & $98,96,93$ & & & & \\
\hline 9 & umc1357 & 1 & 157 & & & & \\
\hline 9 & umc1733 & 1 & 158 & & & & \\
\hline 9 & phi065 & 2 & 144,132 & & & & \\
\hline 9 & bnlg244 & 1 & 159 & & & & \\
\hline 9 & bnlg1525 & 2 & 178,176 & & & & \\
\hline 9 & umc1957 & 1 & 199 & & & & \\
\hline 9 & umc1867 & 2 & 90,88 & & & & \\
\hline 10 & umc1576 & 1 & 136 & & & & \\
\hline 10 & bnlg210 & 1 & 210 & & & & \\
\hline 10 & umc1993 & 1 & 108 & & & & \\
\hline 10 & umc1995 & 1 & 194 & & & & \\
\hline 10 & phi041 & 3 & $137,128,108$ & & & & \\
\hline
\end{tabular}

*Number of cold-specific alleles.

\section{Phylogenetic relationship of high and poorly cold tolerant maize inbred lines}

The eight maize inbred lines clustered into three major phylogenetic groups (Figure 2). Group I included only one high tolerant inbred line (CO439). Group II included five inbred lines that consisted of four high tolerant inbred lines (CO438, CO450, CO435, and CO445), and one poorly tolerant inbred line (CO437). Group III included two poorly tolerant inbred lines (CO436 and CO440). One inbred line (CO437) was not clearly separated from the two major cluster groups. Most of the high tolerant inbred lines were clearly separated from the poorly tolerant inbred lines.



Figure 2. UPGMA dendrogram based on 100 SSR markers in eight high and poorly cold tolerant inbred maize lines. Filled circle: high tolerant inbred lines, open circle: poorly tolerant inbred lines.

Genetics and Molecular Research 15 (4): gmr15049326 


\section{DISCUSSION}

It is an important breeding objective to improve cold tolerance of maize. Much research has been done on phenotypic evaluation of cold tolerance, but few studies have used a genetic approach to identify cold tolerant maize (Hoffman et al., 2015). In a previous study by Farooqi and Lee (2016), maize inbred lines were separated into cold tolerant or cold susceptible lines. In the present study, among eight inbred lines, five were selected for high cold tolerance and three were considered as poorly tolerant (Table 1). Some of the inbred lines used here (CO435, $\mathrm{CO} 436, \mathrm{CO} 437, \mathrm{CO} 439$, and $\mathrm{CO} 440$ ) have been used previously for genetic diversity analysis using SSR markers (Reid et al., 2011).

Until recently, many studies have had to rely on BSA using genetic stocks differing in expression of a particular trait to test the association between the agronomic traits and molecular markers (Quarrie et al., 1999; Fernández-Del-Carmen et al., 2007; Becker et al., 2011; Deschamps et al., 2012; Ye et al., 2015). Populations such as BSA are more easily prepared to identify plants or lines with high or low expression of the trait of interest. In addition, two sets of DNA can be prepared in only a few months, one from the 'high' individuals and the other from the 'low' individuals, and analyzed for allele frequency of molecular markers. BSA has been used previously to discover tolerance mechanisms in maize inbred lines (Quarrie et al., 1999). The major advantages of using BSA include the detection of QTLs from large populations, extreme mapping from disparate ends of a phenotypic range in a population, and the use of near-isogenic lines in specific regions of the genome (Michelmore et al., 1991; Deschamps et al., 2012). Among the many available molecular markers, SSR genotyping can exploit heterosis through detection of variability among inbred lines that can lead to a genetically diverse population source in a maize breeding improvement program (Pinto et al., 2003).

Using genetic diversity analysis, we evaluated MAF, GD, and PIC based on calculations using allele scoring data of SSR loci linked with cold tolerance (Tables 2 and 3, Tables S1 and $\underline{\mathbf{S} 2}$ ). All values were observed to be higher in high cold tolerant inbred maize lines, except MAF (Table 3). The MAF of all lines was found to be 0.47 with mean values of 0.44 and 0.35 in the high and poorly tolerant inbred lines, respectively. These values are lower than those previously reported by Kim et al. (2015) and Sa et al. (2016). By contrast, we observed a GD value of 0.63 , which was relatively higher than that reported by Sa et al. (2016). The average PIC value (0.58) was also significantly lower than that reported by Vaz Patto et al. (2004) and Reid et al. (2011). The possible reason for the observed differences in our genetic diversity analysis values compared to those of previous studies may be due to the smaller number of inbred lines used in our experiment.

In the present study, a considerably lower average $N_{\mathrm{A}}$ per locus (3.19) was also observed compared to previous studies. Vaz Patto et al. (2004) observed 5.3 alleles per locus using 80 SSR loci. Similarly, Warburton et al. (2002) detected 4.9 alleles with 85 SSR markers and Pinto et al. (2003) found 4.16 alleles with 36 SSR markers. Kim et al. (2015) identified 4.44 alleles per locus from the amplification of 1331 alleles among 300 SSR markers. In another study, de Souza et al. (2005) amplified 4.7 alleles per locus. Legesse et al. (2007) identified 104 alleles from 23 SSR markers with a mean of 3.85 alleles per locus. The smaller number of inbred lines used in our experiment might be the reason for detecting fewer alleles per locus. However, Shiri (2011) observed 3.33 average alleles per locus, which is somewhat lower than the other previous studies mentioned above.

Genetics and Molecular Research 15 (4): gmr15049326 
SSR markers were identified as high and poorly cold tolerance-specific alleles (Table 4). Altogether, 319 high and poorly cold tolerant specific alleles were identified. Of these, 128 were high cold tolerance-specific, 61 poorly cold tolerance-specific, and 130 were shared alleles (Figure 1). In our experiment, a total of 84 SSR markers were identified as containing high tolerant specific alleles. The number of high cold tolerant specific alleles ranged from 1-4 for all the high cold tolerant SSR markers. Among total alleles, three high cold specific alleles were found in the umc1124, dupssr21, mmc0251, mmc0181, and phi041 SSR markers. Two specific alleles were detected in 32 SSR markers, and one single allele was detected in 46 markers (Table S2). The maximum $N_{\mathrm{A}}$ was detected in bnlg1273 with sizes ranging from 148-210 bp. Enoki et al. (2002) found bnlg1273 on linkage group 1 with eight alleles using SSR markers when comparing between dent and northern flint inbred lines in cold regions of Japan. Vaz Patto et al. (2004) detected five alleles on umc1013. In another experiment, Rodriguez et al. (2014) used cold specific SSR markers for segregating a population of cold tolerant (EP42) and cold susceptible (A661) maize inbred lines. In our study, 52 SSR markers were detected in cold susceptible maize inbred lines. The number of poorly cold specific alleles ranged from 1-2. Among these, 42 SSR markers contained a single allele and 10 SSRs had two alleles. Zhang et al. (2011) detected QTLs associated with cold tolerance on umc1124, whereas Jompuk et al. (2005) detected cold tolerant QTLs on dupssr21. These specific markers have great potential for identifying cold tolerance in maize.

For the phylogenetic relationships, the eight maize inbred lines clustered into three major groups (Figure 2). Based on the dendrogram, there was clear linkage among the high and poorly cold tolerant lines with the exception of CO439 from the cold tolerant and CO437 from the cold susceptible lines that could not clearly be distinguished from the two major groups. This is in agreement with previous studies that have investigated the genetic basis for the adaptation of maize inbred lines to cold temperatures (Jompuk et al., 2005; Legesse et al., 2007; Reid et al., 2011). Reid et al. (2011) demonstrated that maize inbred lines (CO439, $\mathrm{CO} 435$, $\mathrm{CO} 437$, and $\mathrm{CO} 440$ ) were clustered into different groups. Only CO436 and CO438 were clustered into the same groups. The main cause for differences in linkage among clustering groups is because an inbred line that is related to two other inbred lines from separate clusters will be grouped with the one to which it is most clearly related (Legesse et al., 2007).

In the present study, alleles were identified using BSA and SSR molecular markers specific to poorly and high cold tolerant inbred maize strains (Figure 1). Similar studies have been performed by Quarrie et al. (1999) using BSA and by grouping plants into either high or poorly cold tolerance-specific expression groups according to their particular traits of drought resistance. In another study, Kumar et al. (2014) used BSA to assess high yielding drought tolerance in rice. However, Fernández-Del-Carmen et al. (2007) used a combination of cDNA AFLP and BSA to identify co-segregating genes in a diploid potato population. We can conclude that BSA is an alternative approach that can help identify important traits and markers for cold tolerance in maize. BSA may be a valuable aid for plant breeders in the future.

\section{Conflicts of interest}

The authors declare no conflict of interest.

\section{ACKNOWLEDGMENTS}

Research supported by the Cooperative Research Program for Agriculture Science \&

Genetics and Molecular Research 15 (4): gmr15049326 
Bulk segregant analysis for cold stress resistance in maize

Technology Development (Projects \#PJ01177601 and \#PJ011776) and the Rural Development Administration, Republic of Korea.

\section{REFERENCES}

Becker A, Chao DY, Zhang X, Salt DE, et al. (2011). Bulk segregant analysis using single nucleotide polymorphism microarrays. PLoS One 6: e15993. http://dx.doi.org/10.1371/journal.pone.0015993

de Souza CA, Teles RP, Souto R, Chaves MA, et al. (2005). Endodontic therapy associated with calcium hydroxide as an intracanal dressing: microbiologic evaluation by the checkerboard DNA-DNA hybridization technique. J. Endod. 31: 79-83. http://dx.doi.org/10.1097/01.DON.0000133157.60731.3F

Dellaporta SL, Wood J and Hicks JB (1983). A plant DNA preparation minipreparation version II. Plant Mol. Biol. Report. 1: 19-21. http://dx.doi.org/10.1007/BF02712670

Deschamps S, Llaca V and May GD (2012). Genotyping-by-Sequencing in Plants. Biology (Basel) 1: 460-483. http:// dx.doi.org/10.3390/biology 1030460

Enoki H, Sato H and Koinuma K (2002). SSR analysis of genetic diversity among maize inbred lines adapted to cold regions of Japan. Theor. Appl. Genet. 104: 1270-1277. http://dx.doi.org/10.1007/s00122-001-0857-1

Farooqi MQU and Lee JK (2016). Cold stress evaluation among maize (Zea mays L.) inbred lines in different temperature conditions. Plant Breed. Biotechnol. 4: 352-361. http://dx.doi.org/10.9787/PBB.2016.4.3.352

Farooqi MQU, Ahmad R, Wariach EA and Arfan M (2012). Effect of supplemental foliar applied potassium on yield and grain quality of autumn planted maize (Zea mays L.) under water stress. Int. J. Food Agric. Vet. Sci. 2: 8-12.

Fernández-Del-Carmen A, Celis-Gamboa C, Visser RGF and Bachem CWB (2007). Targeted transcript mapping for agronomic traits in potato. J. Exp. Bot. 58: 2761-2774. http://dx.doi.org/10.1093/jxb/erm140

Frei OM (2000). Changes in yield physiology of corn as a result of breeding in northern Europe. Maydica 45: 173-183.

Guan YJ, Hu J, Wang XJ and Shao CX (2009). Seed priming with chitosan improves maize germination and seedling growth in relation to physiological changes under low temperature stress. J. Zhejiang Univ. Sci. B 10: 427-433. http:// dx.doi.org/10.1631/jzus.B0820373

Gupta PK and Varshney RK (2000). The development and use of microsatellite markers for genetic analysis and plant breeding with emphasis on bread wheat. Euphytica 113: 163-185. http://dx.doi.org/10.1023/A:1003910819967

Hoffman MA, Tranel DM and Hassen AT (2015). Contribution of male inbreds to cold germination in maize hybrids. Seed Sci. Technol. 43: 197-207. http://dx.doi.org/10.15258/sst.2015.43.2.07

Jompuk C, Fracheboud Y, Stamp P and Leipner J (2005). Mapping of quantitative trait loci associated with chilling tolerance in maize (Zea mays L.) seedlings grown under field conditions. J. Exp. Bot. 56: 1153-1163. http://dx.doi. org/10.1093/jxb/eri108

Kim BW, Sa KJ, Park KJ, Park JY, et al. (2015). Genetic analysis of core sets of colored maize and non-colored maize inbred lines using SSR markers. Korean J. Breed. Sci. 47: 54-62. http://dx.doi.org/10.9787/KJBS.2015.47.1.054

Kumar A, Dixit S, Ram T, Yadaw RB, et al. (2014). Breeding high-yielding drought-tolerant rice: genetic variations and conventional and molecular approaches. J. Exp. Bot. 65: 6265-6278. http://dx.doi.org/10.1093/jxb/eru363

Legesse BW, Myburg AA, Pixley KV and Botha AM (2007). Genetic diversity of African maize inbred lines revealed by SSR markers. Hereditas 144: 10-17. http://dx.doi.org/10.1111/j.2006.0018-0661.01921.x

Liu K and Muse SV (2005). PowerMarker: an integrated analysis environment for genetic marker analysis. Bioinformatics 21: 2128-2129. http://dx.doi.org/10.1093/bioinformatics/bti282

Mahajan V, Dhillon BS, Khehra AS and Singh OS (1993). Combining ability of response to cold stress in maize. Field Crops Res. 34: 71-81. http://dx.doi.org/10.1016/0378-4290(93)90112-Z

Matsuoka Y, Mitchell SE, Kresovich S, Goodman M, et al. (2002). Microsatellites in Zea - variability, patterns of mutations, and use for evolutionary studies. Theor. Appl. Genet. 104: 436-450. http://dx.doi.org/10.1007/s001220100694

Mazur P (2004). Principles of cryobiology. In: Life in the frozen state (Fuller BJ, Lane N and Benson EE, eds.). CRC Press, Boca Raton, 3-65.

Michelmore RW, Paran I and Kesseli RV (1991). Identification of markers linked to disease-resistance genes by bulked segregant analysis: a rapid method to detect markers in specific genomic regions by using segregating populations. Proc. Natl. Acad. Sci. USA 88: 9828-9832. http://dx.doi.org/10.1073/pnas.88.21.9828

Mirosavljević M, Čanak P, Ćirić M, Nastasić A, et al. (2013). Maize germination parameters and early seedlings growth under different levels of salt stress. Ratar. Povrt. 50: 49-53.

Nei M and Li W (1979). Mathematical model for studying genetic variation in terms of restriction genetic relationship endonucleases. Proc. Natl. Acad. Sci. USA 76: 5269-5273. http://dx.doi.org/10.1073/pnas.76.10.5269

Genetics and Molecular Research 15 (4): gmr15049326 
Pinto LR, Vieira MLC, De Souza CL, Jr. and De Souza AP (2003). Genetic diversity assessed by microsatellites in tropical maize population submitted to high-density reciprocal recurrent selection. Euphytica 134: 277-286. http://dx.doi. org/10.1023/B:EUPH.0000004946.15260.4a

Quarrie SA, Lazić-Jančić V, Kovačevic D, Steed A, et al. (1999). Bulk segregant analysis with molecular markers and its use for improving drought resistance in maize. J. Exp. Bot. 50: 1299-1306. http://dx.doi.org/10.1093/jxb/50.337.1299

Reid LM, Xiang K, Zhu X, Baum BR, et al. (2011). Genetic diversity analysis of 119 Canadian maize inbred lines based on pedigree and simple sequence repeat markers. Can. J. Plant Sci. 91: 651-661. http://dx.doi.org/10.4141/cjps10198

Revilla P, Malvar RA, Cartea ME, Butrón A, et al. (2000). Inheritance of cold tolerance at emergence and during early season growth in maize. Crop Sci. 40: 1579-1585. http://dx.doi.org/10.2135/cropsci2000.4061579x

Revilla P, Butrón A, Cartea ME, Malvar RA, et al. (2005). Breeding for cold tolerance. In: Abiotic stresses: plant resistance through breeding and molecular approaches (Ashraf M and Harris PJC, eds.). The Haworth Press, New York, 301398.

Riva-Roveda L and Périlleux C (2015). Effects of cold temperatures on the early stages of maize (Zea mays L.). A review. Biotechnol. Agron. Soc. 19: 42-52.

Rohlf FJ (1992). NTSYS-pc: numerical taxonomy and multivariate analysis system, version 1.8. Exter Software, New York.

Rodriguez VM, Butron A, Rady MOA, Soengas P, et al. (2014). Identification of quantitative trait loci involved in the response to cold stress in maize (Zea mays L.). Mol. Breed. 33: 363-371. http://dx.doi.org/10.1007/s11032-013$\underline{9955-4}$

Sa KJ, Ko WR, Kim OG, Ma SJ, et al. (2016). Association analysis and population structure of flowering-related traits in super sweet corn inbred lines with simple sequence repeat markers. Genes Genomics 38: 891. http://dx.doi. org/10.1007/s13258-016-0434-2

Sanghera GS, Wani SH, Hussain W and Singh NB (2011). Engineering cold stress tolerance in crop plants. Curr. Genomics 12: 30-43. http://dx.doi.org/10.2174/138920211794520178

Shiri M (2011). Identification of informative simple sequence repeat (SSR) markers for drought tolerance in maize. Afr. J. Biotechnol. 10: 16414-16420.

Strigens A, Freitag NM, Gilbert X, Grieder C, et al. (2013). Association mapping for chilling tolerance in elite flint and dent maize inbred lines evaluated in growth chamber and field experiments. Plant Cell Environ. 36: 1871-1887. http://dx.doi.org/10.1111/pce.12096

Vaz Patto MC, Satovic Z, Pêgo S and Fevereiro P (2004). Assessing the genetic diversity of Portuguese maize germplasm using microsatellite markers. Euphytica 137: 63-72. http://dx.doi.org/10.1023/B:EUPH.0000040503.48448.97

Warburton ML, Xianchun X, Crossa J, Franco J, et al. (2002). Genetic characterization of CIMMYT inbred maize lines and open pollinated populations using large scale fingerprinting methods. Crop Sci. 42: 1832-1840. http://dx.doi. org $/ 10.2135 /$ cropsci2002.1832

Ye YJ, Liu Y, Cai M, He D, et al. (2015). Screening of molecular markers linked to dwarf trait in crape myrtle by bulked segregant analysis. Genet. Mol. Res. 14: 4369-4380. http://dx.doi.org/10.4238/2015.April.30.10

Zhang X, Tang B, Liang W, Zheng Y, et al. (2011). Quantitative genetic analysis of flowering time, leaf number and photoperiod sensitivity in maize (Zea mays L.). J. Plant Breed. Crop Sci. 3: 168-184.

\section{Supplementary material}

Table S1. Number of alleles and genetic diversity index for SSR loci linked to cold tolerance among maize inbred lines.

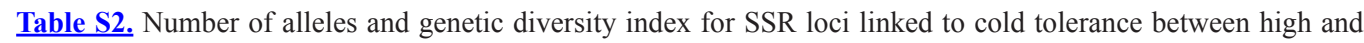
poorly tolerant maize inbred lines.

Genetics and Molecular Research 15 (4): gmr15049326 